\section{Kidney \\ Blood Pressure Research}

\title{
Associations of Usual 24-Hour Sodium and Potassium Intakes with Blood Pressure and Risk of Hypertension among Adults in China's Shandong and Jiangsu Provinces
}

\author{
Jianwei Xu ${ }^{a}$ Xiaorong Chen ${ }^{a}$ Zeng Ge ${ }^{a}$ Hao Liang ${ }^{a} \quad$ Liuxia Yan ${ }^{a} \quad$ Xiaolei Guo \\ Yongqing Zhang ${ }^{c}$ Linhong Wang ${ }^{\text {a }}$ Jixiang Ma ${ }^{a}$
}

${ }^{a}$ National Center for Chronic and Noncommunicable Disease Control and Prevention, Chinese Center for Disease Control and Prevention ,Beijing; bShandong Center for Disease Control and Prevention, Jinan, China, cJiangsu Center for Disease Control and Prevention, Nanjing, China

\section{Key Words}

Sodium • Potassium • Blood pressure • Hypertension • 24-hour urine

\begin{abstract}
Background/Aims: High sodium intake and low intake of potassium can increase blood pressure (BP) and risk of developing hypertension. Few studies have examined the association between 24-h urinary sodium and potassium excretion and BP or risk of hypertension in China, and most used only a single 24-h urinary sample. Methods: We analyzed data on 2281 participants aged 18-69 years by using two 24-h urinary sodium and potassium excretions from the supplemental baseline survey of the Shandong- Ministry of Health Action on Salt Reduction and Hypertension (SMASH) project. We used measurement error models to estimate usual intakes, multivariable linear regression to assess their association with BP, and logistic regression to estimate the risk of hypertension. Results: The average usual intakes of sodium and potassium, and the mean sodium-potassium ratio, were $166.9 \mathrm{mmol} /$ day, 25.3 $\mathrm{mmol} /$ day, and 6.8 , respectively. All three measures were significantly associated with systolic BP (SBP) and diastolic BP (DBP), with an increase of $1.39 \mathrm{mmHg}(95 \%$ confidence interval [CI] $0.44-2.34)$ in SBP and $0.94 \mathrm{mmHg}(95 \%$ CI $0.34-1.55)$ in DBP for a 1-standard deviation (SD) (25.6mmol/day) increase in sodium intake, a decrease of $1.42 \mathrm{mmHg}(95 \% \mathrm{CI}-2.37--0.47)$ in SBP and $0.91 \mathrm{mmHg}(95 \% \mathrm{CI}-1.52--0.30)$ in DBP for a 1-SD (3.4 mmol/day) increase in potassium intake, and an increase of $0.97 \mathrm{mmHg}(95 \%$ CI $0.36-1.58)$ in SBP and of $0.65 \mathrm{mmHg}$ (95\% CI 0.26-1.04) in DBP per unit increase in the sodium-to-potassium ratio. The adjusted odds ratios comparing the risk of hypertension among adults in the highest with those in the lowest quintile differ significantly for potassium (0.51; 95\% CI 0.29-0.88) and sodium-
\end{abstract}




\section{Kidney Blood Pressure Research}

to-potassium ratio (1.40; 95\% CI 1.01-1.94). Conclusions: Our results suggested that higher sodium and lower potassium intakes are associated with increased BP and risk of hypertension in the Shandong and Jiangsu adults.

(C) 2017 The Author(s)

Published by S. Karger AG, Basel

\section{Introduction}

Cardiovascular disease (CVD) is the leading cause of death in China, and hypertension is the key modifiable risk factor for this problem [1, 2]. Hypertension accounts for about $40 \%$ of all deaths [3] and 23\% of the health care costs in China [4], indicating that control of high blood pressure (HBP) must be given high priority in this country. According to estimates obtained in 2014, roughly 270 million Chinese adults have HBP [5]. Various studies have suggested that high sodium and low potassium are among the key risk factors for hypertension [6-10]. In 2010, the mean salt intake of Chinese adults was estimated to be $9.1 \mathrm{~g} /$ day in urban areas and $11.5 \mathrm{~g} /$ day in rural areas [3], both amounts significantly higher than the $6.0 \mathrm{~g} /$ day recommended by the Chinese Nutritional Society [4]. Studies suggest that reducing salt intake is one of the easiest, most efficient and cost-effective ways to reduce the burden of CVD [1, 11-12].

Although the exact mechanisms by which sodium and potassium levels affect blood pressure are not well understood, evidence suggest that the altered sodium and potassium homeostasis play a key role in pathogenesis of hypertension [6]. However, populationbased studies of the associations between sodium and potassium intakes or the sodiumto-potassium ratio and BP or the risk of hypertension among Chinese adults are limited. Most previous studies used just one 24-h urinary sample, thereby not accounting for withinindividual variation in dietary intakes. This lack of adjustment for day-to-day variability increases measurement error and may result in biasing the estimates of the associations toward the null.

In the present study, we estimated the usual sodium and potassium intakes, and the sodium-potassium ratio, in Chinese adults using two 24-h urine collections, and examined their relationships with BP and risk of hypertension.

\section{Materials and Methods}

\section{Study participants}

Our data came from the supplemental baseline survey of the Shandong-Ministry of Health Action on Salt Reduction and Hypertension (SMASH) project, which was conducted at four sites in the Shandong and Jiangsu provinces in 2013. The Gaomi and Fushan sites are in Shandong Province, while the Xinyi and Ganyu sites are located in Jiangsu Province. The 9600 participants, all aged 18-69 y, completed a face-to-face interview to provide sociodemographic and lifestyle information and underwent a physical examination, and a subsample of 2408 participants (25.1\% of total participants) underwent 24 -h urine collections. All of these participants provided a first 24-h urine, and 1445 (60.0\%) provided a second 24-h urine. We excluded, sequentially, 15 participants with missing data on BP or the physical examination and 112 participants with incomplete urine collection, leaving 2281 participants for the present analysis. Our study was conducted according to the Declaration of Helsinki guidelines, and any procedures involving human subjects were approved by the ethics committee of the Chinese Center for Disease Control and Prevention. All participants provided written informed consent.

\section{4-h urine collection}

Following the INTERSALT method [13], we collected two 24-h urines one day apart, i.e., the first collection day was followed by a day without collection and then a second collection day. Participants were given a standard plastic container that contained boric acid (around $1.0 \mathrm{~g}$ ) as a preservative and were provided both written and verbal instructions for the urine collection. The first urine of the day was discarded, and then all urine over the remainder of the 24 -h period was collected. The supervising health 


\section{Kidney \\ Blood Pressure Research}

Kidney Blood Press Res 2017;42:188-200

\begin{tabular}{|l|l}
\hline DOI: $10.1159 / 000475486$ & C 2017 The Author(s). Published by S. Karger AG, Basel
\end{tabular}

Published onlıne: April 25, 2017

www.karger.com/kbr

$\mathrm{Xu} / \mathrm{Chen} / \mathrm{Ge} /$ Liang et al.: Novel Genes and Pathways in Neonatal Ureteral Obstruction

professional recorded the beginning and ending time for each urine collection and the total hours between the first and last void collected. A standard questionnaire was orally administered to each participant at the end of the 24-h period to assess the completeness of urine collection. Total volume of the collection was measured, and urine aliquots were stored at $-20^{\circ} \mathrm{C}$ before being transported frozen to a certified laboratory (ADICON Clinical Laboratory Inc., Jinan, China). In accordance with the standard procedure, urinary sodium and potassium were measured with the ion-selective electrode method using the Olympus AU 680 autoanalyzer (the coefficient of variation [CV] was $1.5 \%$ for sodium and $2.5 \%$ for potassium). Creatinine was measured with the picric acid method using the Olympus AU 640 analyzer (the CV was 3.0\%). An incomplete urine collection was defined as either a 24-h urinary volume less than $500 \mathrm{ml}$ or a 24-h urinary creatinine volume that was \pm 2 standard deviations (SD) outside of the sex-specific mean.

\section{Estimating usual intakes of sodium and potassium}

Of the 2281 participants eligible for analysis, 1356 (59\%) provided a reliable second 24-h urine. We used PC-SIDE software (Software for Intake Distribution Estimation for the Windows OS, Version 1.0, Iowa State University) to estimate the usual intake of sodium, potassium, and their ratio [14]; this method requires that at least some participants have multiple days of intake values. We estimated the usual intake while adjusting for the period of the week when the 24-h urine was collected and for the covariates listed below, and estimated the best linear unbiased predictors of usual sodium and potassium intake and their ratio for association study.

\section{Outcome measures}

BP was measured three times using an electronic sphygmomanometer (HEM-7071, Omron Corporation, Japan), with the average of the three measures used for analyses. Hypertension was defined per the Chinese guidelines on preventing and controlling hypertension and the United States Seventh Report of the Joint National Committee on Prevention, Detection, Evaluation, and Treatment of High Blood Pressure (JNC-7) as the presence of one or more of the following characteristics: an average SBP $\geq 140 \mathrm{mmHg}$, average DBP $\geq 90$ $\mathrm{mmHg}$, a prior diagnosis of hypertension, or taking antihypertensive medication [15-16].

\section{Covariates}

The covariates included age, sex, study site, educational attainment, occupation, smoking status, drinking status (alcoholic beverages), physical activity, body mass index (BMI), and use of antihypertensive medication. There were four study sites, two each in Shandong and Jiangsu provinces; educational attainment was classified in years as <6, 6-9, and >9; occupations: farmers, workers, household workers, and other; drinking status as: nondrinker and drinker; physical activity was defined by leisure-time exercise and classified as either active or inactive; smoking status as: none or current smoker. The BMI was calculated as weight in kilograms divided by height in meters squared $\left(\mathrm{kg} / \mathrm{m}^{2}\right)$. Normal weight was defined as a BMI $<24$, while overweight was defined as a BMI 24 to $<28$, and BMI $\geq 28$ as obese [16].

\section{Statistical analysis}

We calculated the mean, standard deviation (SD) and standard error (SE), percentages, and 95\% confidence intervals (CIs) for the intake of sodium and potassium, the sodium-potassium ratio, and selected covariates. We used multivariable linear regression to examine the associations with SBP and DBP of usual sodium intake, usual potassium intake, and their ratio. We estimated the adjusted $\beta$-coefficients of changes in SBP or DBP associated with a 1-standard deviation (SD) increase in urinary sodium or potassium and a 1-unit change in the sodium-potassium ratio.

In fitting a restricted cubic spline function [17] while adjusting for covariates to examine the doseresponse relationship between (a) values for urinary sodium and potassium as well as the sodiumpotassium ratio and (b) BP and risk of hypertension, we found no evidence of a significant departure from linearity for the three intake variables of interest. Thus, we calculated the $10^{\text {th }}-30^{\text {th }}-, 50^{\text {th }}-, 70^{\text {th }}-$, and $90^{\text {th }}$ percentile distributions of the estimated usual intakes and, using the parameters from the linear regression models, estimated the adjusted mean SBP and DBP for these five distributions. These adjusted means can be interpreted as the middle value of each quintile (Q1, Q2, Q3, Q4, and Q5). For risk of hypertension, we used multivariable logistic regression analysis to estimate adjusted odds ratios (AORs) comparing Q5, Q4, Q3, and Q2 to the lowest quintile (Q1) using an approach similar to that used in the linear regression models. In both our linear and logistic regression analyses, we developed three covariate-adjusted models. In model 


\section{Kidney Blood Pressure Research}

Kidney Blood Press Res 2017;42:188-200

\begin{tabular}{l|l}
\hline DOI: $10.1159 / 000475486$ & (C) 2017 The Author(s). Published by S. Karger AG, Basel
\end{tabular}

Published onlıne: April 25, 2017

www.karger.com/kb

1 , we adjusted for age, sex, and study site; in model 2, in addition to the covariates in model 1, we adjusted for educational attainment, occupation, smoking status, drinking status, physical activity, and use of antihypertensive medication; in model 3, we further adjusted for BMI as a continuous variable. We adjusted for sodium intake in the regression models for potassium and for potassium intake in the regression models for sodium; we did not make these adjustments in the regression models for the sodium-to-potassium ratio. We tested the interaction between the estimated usual intakes and covariates by including the interaction terms in the regression models while accounting for the multiple comparisons. We found no evidence of significant interaction.

We conducted several sensitivity analyses. First, we repeated the analysis using the World Health Organization (WHO) criterion (ratio of urinary creatinine [mg/d] to body weight $[\mathrm{kg}]$ of $<10.8$ or $>25.2$ ) [18] and the Reinivuo criterion (urinary creatinine level $<6 \mathrm{mmol} / \mathrm{d}$ plus a total urine volume $<1000 \mathrm{ml} / \mathrm{d}$ or with a urinary excretion $<5 \mathrm{mmol} / \mathrm{d}$ as having incomplete urine) [19] for incompleteness of urine collection based on excretion of urinary creatinine and other variables (see Tables 5-8). Second, we repeated our analysis by excluding the participants who were taking an antihypertensive medication. Awareness of their hypertension status might have changed their intake of sodium, and some BP-lowering medications could affect values for sodium or potassium excretion (see Table 9, 10). Statistical analyses were performed with SAS 9.3 (SAS Institute Inc.); all tests were 2 -sided, and a $p$ value $<0.05$ was considered significant.

\section{Results}

The mean age of the 2281 participants was 42.1 years (SD=13.4). More than half of the participants (56.9\%) were overweight or obese, and 37.0\% (95\% CI 35.0-38.9\%) had hypertension (Table 1). Overall, the participants' average estimated usual intakes of sodium and potassium and the sodium-to-potassium ratio were $166.9 \mathrm{mmol} /$ day, $25.3 \mathrm{mmol} /$ day, and 6.8, respectively, and none of these values differed by BMI or hypertension status (Table 2). Mean sodium intake was higher among participants $<50$ years of age, Ganyu study site, with 6-9 years of education, current smokers and drinking alcohol, physically inactive and obesity (Table 2).

After adjustment for potential confounders (Table 3, Model 3), intake of sodium, potassium, and their ratio were all significantly associated with SBP, with an increase of $1.39 \mathrm{mmHg}(95 \% \mathrm{CI} 0.44-2.34)$ for a $1-\mathrm{SD}$ increase ( $\mathrm{SD}=25.6 \mathrm{mmol}$ ) in sodium intake and a decrease of $1.42 \mathrm{mmHg}(95 \% \mathrm{CI}-2.37-0.47)$ for a $1-\mathrm{SD}(\mathrm{SD}=3.4 \mathrm{mmol})$ increase in potassium intake. There was an increase of $0.97 \mathrm{mmHg}(95 \% \mathrm{CI} 0.36-1.58)$ for a 1-unit increase in the sodium-to-potassium ratio. For DBP, a 1-SD increase in sodium intake was associated with a $0.94 \mathrm{mmHg}(95 \% \mathrm{CI} 0.34-1.55)$ increase in that value, and a 1 -SD increase in potassium intake was associated with a decrease of $0.91 \mathrm{mmHg}(95 \% \mathrm{CI}-1.52-0.30)$. Finally, there was an increase of $0.65 \mathrm{mmHg}$ in DBP (95\% CI 0.26-1.04) with a 1-unit increase in the sodium-to-potassium ratio.

The adjusted average SBP among the participants ranged from $128.9 \mathrm{mmHg}$ (95\% CI 127.1-130.6) among those in the lowest to $134.3 \mathrm{mmHg}$ (95\% CI 132.3-136.4) among those in the highest quintile (Fig. 1A); from $134.0 \mathrm{mmHg}$ (95\% CI 132.2-135.9) among those in the lowest to $128.5 \mathrm{mmHg}$ (95\% CI 126.5-130.5) among those in the highest quintile of potassium intake (Fig. 1B); and from $129.8 \mathrm{mmHg}$ (95\% CI 128.6-131.0) among those in the lowest to $133.3 \mathrm{mmHg}$ (95\% CI 131.9-134.6) among those in the highest quintile of sodiumto-potassium ratio (Fig. 1C).

The adjusted ORs comparing the prevalence of hypertension among adults in the highest quintile with those in the lowest quintile did not reveal significant differences for sodium intake (1.57; 95\% CI 0.89-2.75), but significant difference for potassium intake (0.51; 95\% CI 0.29-0.88), or the sodium-potassium ratio (1.40; 95\% CI 1.01-1.94) (Table 4).

In sensitivity analyses, we repeated our analyses using two alternative measures of incompleteness of urine collection (the WHO and Reinivuo criteria). Overall, the patterns of the associations remained largely unchanged (see Table 5-8), although the adjusted OR comparing the prevalence of hypertension among adults in the highest vs. those in the lowest quintile was significant (AOR 1.95; 95\% CI 1.02-3.71) for sodium intake using the WHO 


\section{Kidney Blood Pressure Research}

Table 1. Characteristics of participants in 2013 supplemental survey of the SMASH project

\begin{tabular}{|c|c|c|c|c|c|c|}
\hline \multirow[b]{2}{*}{ Characteristic } & \multicolumn{2}{|c|}{ All participants } & \multicolumn{2}{|r|}{ Male } & \multicolumn{2}{|r|}{ Female } \\
\hline & $\mathrm{N}$ & $\begin{array}{c}\text { Mean (SD) } \\
\text { or \% (95\% CI) }\end{array}$ & $\mathrm{N}$ & $\begin{array}{c}\text { Mean (SD) } \\
\text { or } \%(95 \% \mathrm{CI})\end{array}$ & $\mathrm{N}$ & $\begin{array}{c}\text { Mean (SD) } \\
\text { or \% (95\% CI) }\end{array}$ \\
\hline Age (years) & 2281 & $42.1(13.4)$ & 1135 & $42.2(13.5)$ & 1146 & $41.9(13.4)$ \\
\hline \multicolumn{7}{|l|}{ region } \\
\hline Fushan & 551 & $24.2(21.8-26.7)$ & 295 & $26.0(23.4-28.5)$ & 256 & $22.3(19.9-24.8)$ \\
\hline Gaomi & 568 & $24.9(22.4-27.3)$ & 294 & $25.9(23.4-28.5)$ & 274 & $23.9(21.4-26.4)$ \\
\hline Xinyi & 598 & $26.2(23.1-29.6)$ & 272 & $24.0(21.5-26.5)$ & 326 & $28.5(25.8-31.1)$ \\
\hline Ganyu & 564 & $24.7(22.3-27.1)$ & 274 & $24.1(21.7-26.6)$ & 290 & $25.3(22.8-27.8)$ \\
\hline \multicolumn{7}{|l|}{ Years of education } \\
\hline $0-6$ & 822 & $36.0(34.1-38.1)$ & 304 & $26.7(24.2-29.4)$ & 518 & $45.2(42.3-48.1)$ \\
\hline $6-9$ & 917 & $40.2(38.2-42.3)$ & 509 & $44.9(42.0-47.7)$ & 408 & $35.6(32.8-38.4)$ \\
\hline$>9$ & 542 & $23.8(22.0-25.6)$ & 322 & $28.4(25.8-31.0)$ & 220 & $19.2(16.9-21.5)$ \\
\hline \multicolumn{7}{|l|}{ Occupation } \\
\hline Farmer & 869 & $38.1(36.1-40.1)$ & 443 & $39.0(36.2-41.9)$ & 426 & $37.2(34.4-40.0)$ \\
\hline Worker & 569 & $25.0(23.1-26.8)$ & 374 & $33.0(30.2-35.7)$ & 195 & $17.0(14.8-19.2)$ \\
\hline Household worker & 368 & $16.1(13.4-19.4)$ & 34 & $3.0(2.0-4.0)$ & 334 & $29.1(26.5-31.8)$ \\
\hline Other & 475 & $20.8(5.8-10.5)$ & 284 & $25.0(22.5-27.5)$ & 191 & $16.7(14.5-18.8)$ \\
\hline \multicolumn{7}{|l|}{ Smoking } \\
\hline No & 1614 & $70.8(68.9-72.6)$ & 491 & $43.3(40.4-46.1)$ & 1123 & $98.0(97.2-98.8)$ \\
\hline Yes & 667 & $29.2(27.4-31.1)$ & 644 & $56.7(53.9-59.6)$ & 23 & $2.0(1.2-2.8)$ \\
\hline \multicolumn{7}{|l|}{ Drinking status } \\
\hline Nondrinker & 1682 & $73.7(71.9-75.6)$ & 561 & $49.4(46.5-52.3)$ & 1121 & $97.8(97.0-99.0)$ \\
\hline Drinker & 599 & $26.3(24.5-28.1)$ & 574 & $50.6(47.7-53.5)$ & 25 & $2.2(1.3-3.0)$ \\
\hline \multicolumn{7}{|l|}{ Physical activity } \\
\hline Inactive & 1810 & $79.4(77.7-81.0)$ & 899 & $79.2(76.9-81.6)$ & 911 & $79.5(77.2-81.8)$ \\
\hline Active & 471 & $20.6(19.0-22.3)$ & 236 & $20.8(18.4-23.2)$ & 235 & $20.5(18.2-22.8)$ \\
\hline \multicolumn{7}{|l|}{ BMI } \\
\hline Normal & 982 & $43.1(41.0-45.1)$ & 480 & $42.3(39.4-45.2)$ & 502 & $43.8(40.9-46.7)$ \\
\hline Overweight & 860 & $37.7(35.7-39.7)$ & 458 & $40.4(37.5-43.2)$ & 402 & $35.1(32.3-37.8)$ \\
\hline Obese & 439 & $19.2(17.6-20.9)$ & 197 & $17.3(15.2-19.6)$ & 242 & $21.1(18.8-23.5)$ \\
\hline SBP & 2281 & $131.4(19.9)$ & 1135 & $134.6(18.0)$ & 1146 & $128.2(21.1)$ \\
\hline DBP & 2281 & $83.6(11.9)$ & 1135 & $85.9(11.9)$ & 1146 & $81.3(11.5)$ \\
\hline \multicolumn{7}{|l|}{ Hypertension } \\
\hline No & 1438 & $63.0(61.1-65.0)$ & 634 & $55.9(53.0-58.8)$ & 804 & $70.2(67.5-72.8)$ \\
\hline Yes & 843 & $37.0(35.0-38.9)$ & 501 & $44.1(41.3-47.0)$ & 342 & $29.8(27.2-32.5)$ \\
\hline
\end{tabular}

criterion (Table 6). We also repeated the analysis by excluding the participants who were on antihypertensive medications, with the results remaining largely unchanged (Table 9, 10).

\section{Discussion}

In this study, we found that usual sodium intake and the sodium-potassium ratio were positively associated with both SBP and DBP, and potassium intake negatively associated with both measures. For risk of hypertension, only potassium intake (a negative association) and the sodium-potassium ratio (positive) had a significant association, but the association with sodium intake became significant (positive) after we employed the WHO criterion for completeness of urine collection (Table 6).

Our finding of a positive association between sodium intake and BP is consistent with results from animal experiments, epidemiological studies, and clinical trials [20-24]. In addition, a recent meta-analysis of 34 trials reported that a reduction of $75 \mathrm{mmol}$ per 24 -h in urinary sodium excretion reduced SBP by an average of $4.18 \mathrm{mmHg}(95 \% \mathrm{CI}-5.18--3.18)$ and DBP by an average of $2.06 \mathrm{mmHg}(95 \% \mathrm{CI}-2.67-$-1.45) [13], findings similar to ours. In our study, the slope of the overall relationship between usual sodium intake and BP (equivalent to an increase of $2.36 \mathrm{mmHg}$ in SBP and $1.60 \mathrm{mmHg}$ in DBP per g increase in sodium intake) 


\section{Kidney Blood Pressure Research}

is more steeper than the results of the INTERSALT study (increment of 2.2 $\mathrm{mmHg}$ in SBP and $0.1 \mathrm{mmHg}$ in DBP per $100 \mathrm{mmol} / \mathrm{d}$ sodium) [25] and PURE study (increment of $2.11 \mathrm{mmHg}$ in SBP and $0.78 \mathrm{mmHg}$ in DBP per g of sodium [26].

Unlike the INTERSALT and PURE studies, however, we estimated the associations of BP with usual sodium intake while accounting for withinindividual variation in such intake. The significant inverse relationship we found between potassium excretion and BP (equivalent to a decrease of $10.7 \mathrm{mmHg}$ in SBP and $6.86 \mathrm{mmHg}$ in DBP per g) is substantially steeper than that reported in the INTERSALT study (decrements of $0.65 \mathrm{mmHg}$ in SBP and $0.42 \mathrm{mmHg}$ in DBP per g) and PURE study (decrements of $0.75 \mathrm{mmHg}$ in SBP and $0.06 \mathrm{mmHg}$ in DBP per g). The reason for the steep association between potassium and $\mathrm{BP}$ in this study is probably the very low potassium intake, which makes this population very sensitive to an increased intake in potassium. The PURE study also found a stronger inverse relationship between potassium excretion and BP in China than in other geographic regions in that study. A recent metaanalysis, however, reported that an increased potassium intake had no statistically significant effect on BP [28]. And yet, other meta-analyses reported that an increased potassium intake lowered BP in patients both with and without hypertension [8, 29-30]. A WHO-sponsored
Kidney Blood Press Res 2017;42:188-200

\begin{tabular}{l|l}
\hline DOI: $10.1159 / 000475486$ & (C) 2017 The Author(s). Published by S. Karger AG, Basel
\end{tabular}

Published onIIne: April 25, 2017 www.karger.com/kb

Table 2. Usual intakes of sodium and potassium and sodium-potassium ratio by characteristics

\begin{tabular}{|c|c|c|c|}
\hline \multirow[t]{2}{*}{ Characteristics } & $\begin{array}{l}\text { 24-h sodium } \\
\text { excretion } \\
(\mathrm{mmol}) \\
\end{array}$ & $\begin{array}{c}\text { 24-h potassium } \\
\text { excretion } \\
(\mathrm{mmol}) \\
\end{array}$ & $\begin{array}{l}\text { Sodium- } \\
\text { potassium } \\
\text { ratio } \\
\end{array}$ \\
\hline & Mean(SD) & Mean(SD) & Mean(SD) \\
\hline All & $166.9(25.6)$ & $25.3(3.4)$ & $6.8(1.5)$ \\
\hline \multicolumn{4}{|l|}{ Sex } \\
\hline Male & $172.4(29.0)$ & $25.3(3.6)$ & $7.0(1.6)$ \\
\hline Female & $161.6(22.0)$ & $25.3(3.0)$ & $6.5(1.4)$ \\
\hline \multicolumn{4}{|l|}{ Age, years } \\
\hline$<50$ & $169.7(26.9)$ & $24.9(3.6)$ & $7.0(1.6)$ \\
\hline$\geq 50$ & $160.7(20.3)$ & $26.3(3.3)$ & $6.3(1.3)$ \\
\hline$p$-value & $<0.001$ & $<0.001$ & $<0.001$ \\
\hline \multicolumn{4}{|l|}{ Region } \\
\hline Fushan (1) & $170.4(36.8)$ & $23.8(4.3)$ & $7.4(1.9)$ \\
\hline Gaomi (2) & $138.7(23.5)$ & $23.0(2.8)$ & $6.2(1.4)$ \\
\hline Xinyi (3) & $178.8(18.3)$ & $26.2(2.2)$ & $6.9(1.1)$ \\
\hline Ganyu (4) & $180.8(21.3)$ & $28.2(2.8)$ & $6.6(1.3)$ \\
\hline$p$-value (1) vs. (2) & $<0.001$ & $<0.001$ & $<0.001$ \\
\hline$p$-value (1) vs. (3) & $<0.001$ & $<0.001$ & $<0.001$ \\
\hline$p$-value (1) vs. (4) & $<0.001$ & $<0.001$ & $<0.001$ \\
\hline \multicolumn{4}{|c|}{ Educational attainment } \\
\hline $0 \sim 6$ & $164.3(21.9)$ & $25.8(2.8)$ & $6.5(1.3)$ \\
\hline $6 \sim 9$ & $174.1(21.5)$ & $26.7(3.1)$ & $6.7(1.4)$ \\
\hline$>9$ & $159.1(35.2)$ & $22.4(3.5)$ & $7.3(1.8)$ \\
\hline$p$-value for trend $\mathrm{d}^{\mathrm{a}}$ & $<0.001$ & $<0.001$ & $<0.001$ \\
\hline \multicolumn{4}{|l|}{ Occupation } \\
\hline Peasant (1) & $163.4(20.0)$ & $25.5(3.0)$ & $6.5(1.4)$ \\
\hline Worker (2) & $170.2(30.3)$ & $24.8(3.5)$ & $7.0(1.4)$ \\
\hline Household (3) ${ }^{\mathrm{b}}$ & $164.2(18.2)$ & $26.5(2.2)$ & $6.3(1.2)$ \\
\hline Others (4) & $171.2(35.4)$ & $24.5(3.3)$ & $7.1(1.7)$ \\
\hline$p$-value (1) vs. (2) & 0.01 & 0.001 & $<0.001$ \\
\hline$p$-value (1) vs. (3) & 0.66 & 0.002 & 0.06 \\
\hline$p$-value (1) vs. (4) & 0.03 & $<0.001$ & $<0.001$ \\
\hline \multicolumn{4}{|l|}{ Smoking status } \\
\hline Yes $^{b}$ & $172.6(26.8)$ & $25.3(3.4)$ & $7.1(1.5)$ \\
\hline No & $164.6(24.5)$ & $25.3(3.4)$ & $6.7(1.5)$ \\
\hline$p$-value & $<0.001$ & 1.00 & $<0.001$ \\
\hline \multicolumn{4}{|l|}{ Drinking status } \\
\hline Drinker $^{b}$ & $175.6(28.4)$ & $25.8(3.6)$ & $7.0(1.4)$ \\
\hline Nondrinker & $163.9(24.5)$ & $25.2(3.2)$ & $6.7(1.5)$ \\
\hline$p$-value & $<0.001$ & 0.02 & $<0.001$ \\
\hline \multicolumn{4}{|l|}{ Physical activity } \\
\hline Inactive & $168.4(23.6)$ & $25.7(3.5)$ & $6.7(1.4)$ \\
\hline Active & $161.6(31.3)$ & $24.0(3.2)$ & $6.9(1.8)$ \\
\hline$p$-value ${ }^{\text {a }}$ & $<0.001$ & $<0.001$ & 0.01 \\
\hline \multicolumn{4}{|l|}{ BMI } \\
\hline Normal & $160.3(24.6)$ & $24.2(3.4)$ & $6.8(1.6)$ \\
\hline Overweight & $170.3(26.9)$ & $26.0(3.3)$ & $6.7(1.4)$ \\
\hline Obesity & $175.2(20.9)$ & $26.5(3.0)$ & $6.8(1.4)$ \\
\hline$p$-value for trend ${ }^{\mathrm{a}}$ & $<0.001$ & $<0.001$ & 0.25 \\
\hline \multicolumn{4}{|c|}{$\begin{array}{l}\text { All participants }(\mathrm{n}=2281) \text {. a For categorical variable with two } \\
\text { categories, P value based on T-test; for categories of the continuous } \\
\text { variables in nature (e.g., years of education and body mass index), P } \\
\text { value for difference across the categories; for categorical variables } \\
\text { (e.g., study sites), we presented pairwise P values. All tests were 2- } \\
\text { tailed. b "-":sample size is too small to estimate the usual intake. }\end{array}$} \\
\hline
\end{tabular}




\section{Kidney Blood Pressure Research}

Table 3. Adjusted associations between usual intake of sodium, potassium, and sodium-potassium ratio and systolic and diastolic blood pressure

Table 4. Adjusted odds ratios for risk of hypertension by estimated usual sodium and potassium intakes and sodium-potassium ratio

$\nabla$

\begin{tabular}{|c|c|c|c|c|}
\hline & \multicolumn{2}{|c|}{ Systolic Blood Pressure } & \multicolumn{2}{|c|}{ Diastolic Blood Pressure } \\
\hline & $\begin{array}{c}\beta \text {-coefficient } \\
(95 \% \mathrm{CI})^{\mathrm{a}}\end{array}$ & $\begin{array}{c}p- \\
\text { Value }\end{array}$ & $\begin{array}{c}\beta \text {-coefficient } \\
(95 \% \mathrm{CI})^{\mathrm{a}}\end{array}$ & $p$-Value \\
\hline \multicolumn{5}{|l|}{ Sodium } \\
\hline Model 1b & $1.85(0.86-2.83)$ & 0.0003 & $1.29(0.64-1.93)$ & $<0.0001$ \\
\hline Model 2c & $1.70(0.71-2.69)$ & 0.0008 & $1.19(0.55-1.83)$ & 0.0003 \\
\hline Model 3d & $1.39(0.44-2.34)$ & 0.0042 & $0.94(0.34-1.55)$ & 0.0023 \\
\hline \multicolumn{5}{|l|}{ Potassium } \\
\hline Model 1b & $-1.22(-2.21--0.23)$ & 0.0158 & $-0.70(-1.34--0.06)$ & 0.0324 \\
\hline Model 2c & $-1.07(-2.06--0.08)$ & 0.0348 & $-0.64(-1.28-0.01)$ & 0.0524 \\
\hline Model 3d & $-1.42(-2.37--0.47)$ & 0.0033 & $-0.91(-1.52--0.30)$ & 0.0033 \\
\hline \multicolumn{5}{|c|}{ Sodium-potassium ratio } \\
\hline Model $1^{\mathrm{b}}$ & $1.08(0.46-1.70)$ & 0.0006 & $0.70(0.30-1.11)$ & 0.0007 \\
\hline Model $2^{c}$ & $1.02(0.39-1.66)$ & 0.0016 & $0.69(0.28-1.10)$ & 0.0011 \\
\hline Model 3d & $0.97(0.36-1.58)$ & 0.0019 & $0.65(0.26-1.04)$ & 0.0011 \\
\hline
\end{tabular}

a $\beta$-coefficients for the usual intake of sodium and potassium are presented as per 1 standard deviation (SD) of intake; the estimated population SD for 24-h sodium and 24 -h potassium was $25.6 \mathrm{mmol}$ and $3.4 \mathrm{mmol}$, respectively. The $\beta$-coefficient for the sodium-potassium ratio is presented as per 1 unit of change. bModel 1 adjusted for age, sex, and study site. In addition, potassium intake was included in the model for sodium and sodium intake in the model for potassium. cModel 2 adjusted for all factors in Model 1 plus educational attainment, occupation, smoking status, drinking status, physical activity, and use of antihypertensive medication. dModel 3 adjusted for all factors in Model 2 plus BMI as a continuous variable.

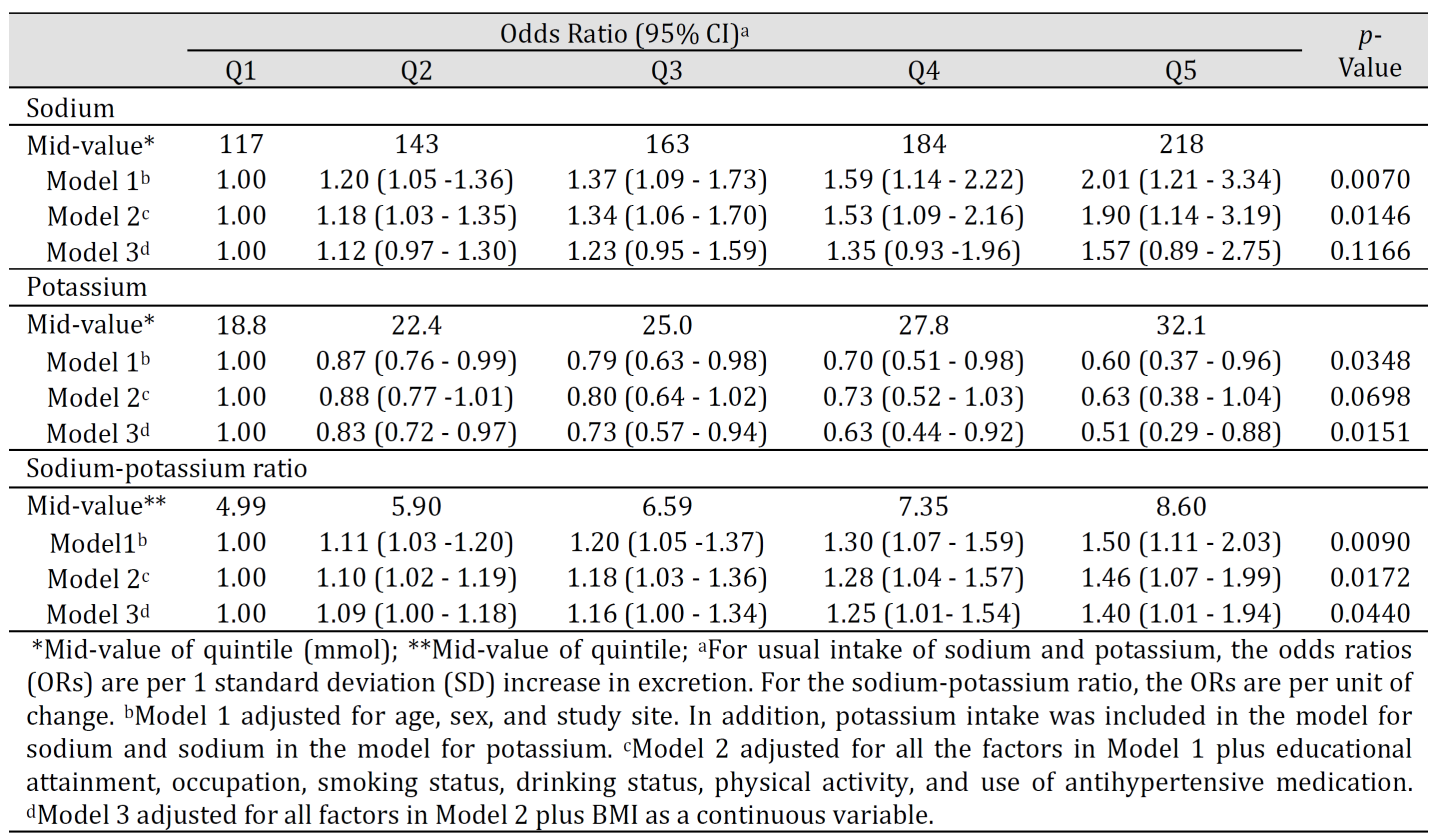

study [31] showed an added complexity of the relationship between potassium and BP, as it found that potassium intake was negatively associated with both SBP and DBP in Tibetan participants but was positively associated with SBP and DBP in Han participants (Han is the majority ethnicity in China). The WHO study focused on people aged 48-56 years and had a limited sample size $(n=800)$ [31].

We found that the sodium-to-potassium ratio was significantly associated with SBP, DBP, and risk of hypertension, with increments of $0.97 \mathrm{mmHg}$ in SBP and $0.65 \mathrm{mmHg}$ in DBP per a 1-unit increase in the ratio. These results are consistent with previous studies [32]. 


\section{Kidney \\ Blood Pressure Research}

Kidney Blood Press Res 2017;42:188-200

\begin{tabular}{l|l}
\hline DOI: $10.1159 / 000475486$ & (c) 2017 The Author(s). Published by S. Karger AG, Basel
\end{tabular}

Published onlıne: April 25, 2017 www.karger.com/kbr

The PURE study found that a 1-SD increment in the estimated sodiumto-potassium ratio $(\mathrm{SD}=3.26)$ was associated with increments of 2.3 $\mathrm{mmHg}$ in SBP and $0.78 \mathrm{mmHg}$ in DBP. The 2005-2010 NHANES study [31] found that the sodium-to-potassium ratio was associated with SBP, with an increase of $1.05 \mathrm{mmHg}$ (95\% CI $0.12-1.98$ ) for every 0.5 -unit increase in this ratio. The China Health and Nutrition Survey cohort study found that a high sodium-to-potassium ratio had a strong independent dose-response association with incident hypertension. The findings there suggested that the sodium-topotassium ratio might be a better measurement than either sodium or potassium alone in the evaluation of BP outcomes and incident hypertension [33]. In addition, a recent meta-analysis found that among the randomized controlled trials reviewed, the sodium-topotassium ratio appeared to be more strongly associated with BP than either sodium or potassium intake alone in the hypertensive adult population [32].

Our study found that both potassium intake and the sodiumto-potassium ratio were significantly associated with risk of hypertension. The 2005-2010 NHANES found that the AORs for comparisons of the prevalence of hypertension among adults in the highest quartile of intake vs. the lowest quartile were 1.40 (95\% CI 1.07-1.83) for sodium and 0.72

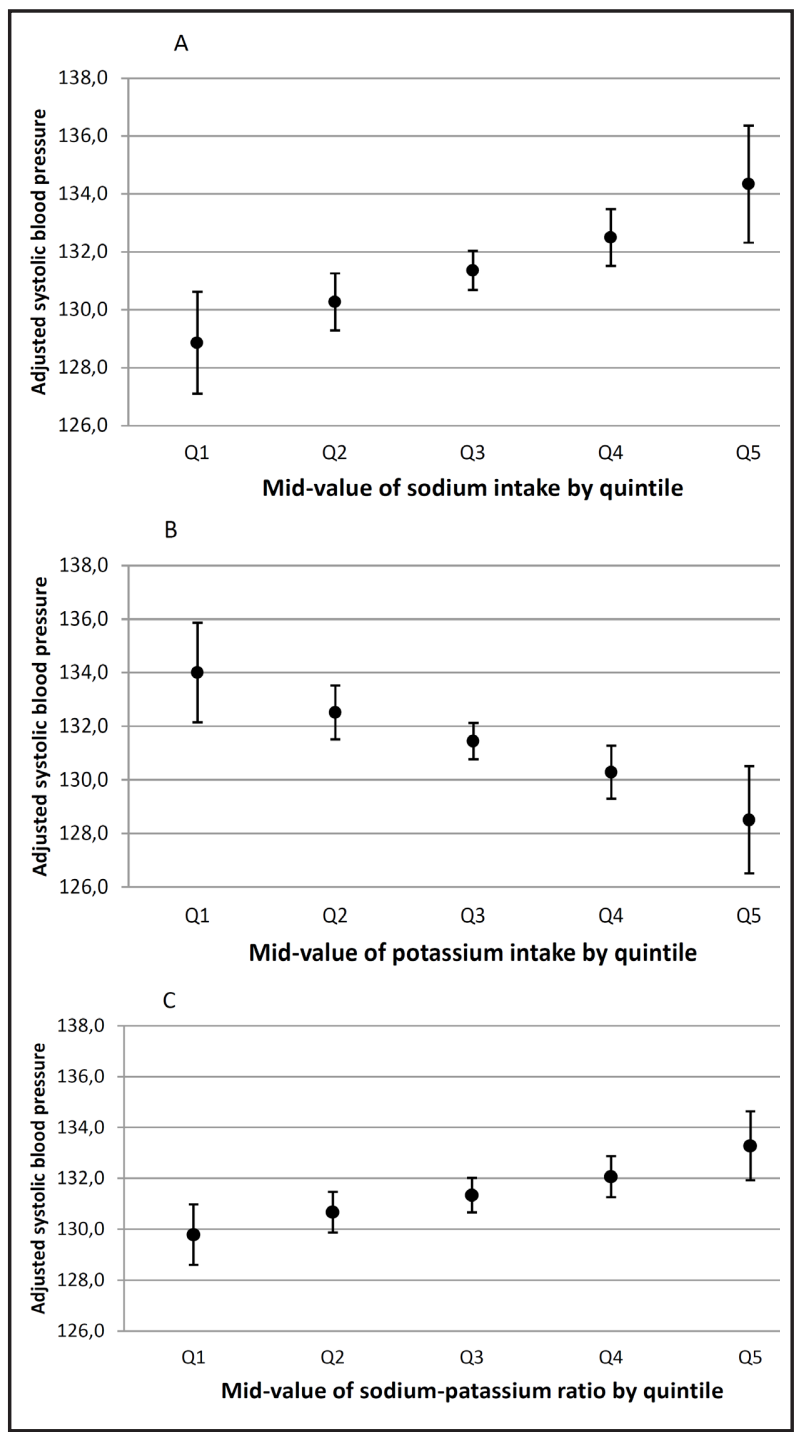

Fig. 1. Adjusted systolic blood pressure (with 95\% confidence interval) by mid-value of quintile of usual sodium intake (panel A), potassium intake (panel B), and sodium-potassium ratio (panel $\mathrm{C}$ ). (95\% CI 0.53-0.97) for potassium, while the AOR for the sodium-to-potassium ratio using this comparison was 1.30 (95\% CI 1.05-1.61 [27]. Elsewhere, the China Health and Nutrition Survey cohort study, which compared intake in the highest against the lowest quintile, the AOR for incident hypertension was 1.84 (95\% CI 1.56-2.16) for sodium, 0.66 (95\% CI 0.56-0.78) for potassium, and 2.14 (95\% CI 1.79-2.55) for their ratio [33]. Our results were similar to these two studies, but we found an insignificant association between sodium intake and hypertension after we adjusted for covariates. However, the association became significant after we used the WHO criterion for completeness of urine collection (Table 6).

Our study had several major strengths. First, to our knowledge, this is the first study to assess the association between usual intakes of salt and potassium and both BP and risk of hypertension using two 24-h collections of urine in a relatively large sample of Chinese adults. Having two urine collections rather than just one should have accounted for, at least partly, the between- and within-individual variation in sodium and potassium intakes. 


\section{Kidney Blood Pressure Research}

Table 5. Adjusted associations between usual intakes of sodium and potassium and the sodium-potassium ratio and systolic and diastolic blood pressure using the WHO criterion

Table 6. Adjusted odds ratios for hypertension by estimated usual sodium and potassium intake and sodium-potassium ratio using the WHO criterion V

\begin{tabular}{|c|c|c|c|c|}
\hline & \multicolumn{2}{|c|}{ Systolic Blood Pressure } & \multicolumn{2}{|c|}{ Diastolic Blood Pressure } \\
\hline & $\begin{array}{c}\beta \text {-coefficient } \\
(95 \% \mathrm{CI})^{\mathrm{a}}\end{array}$ & $p$-Value & $\begin{array}{c}\beta \text {-coefficient } \\
(95 \% \mathrm{CI})^{\mathrm{a}}\end{array}$ & $p$-Value \\
\hline \multicolumn{5}{|l|}{ Sodium } \\
\hline Model $1^{\mathrm{b}}$ & $1.80(0.69-2.91)$ & 0.0016 & $1.27(0.55-2.00)$ & 0.0006 \\
\hline Model 2c & $1.68(0.56-2.79)$ & 0.00 & $1.21(0.48-1.93)$ & 0.0012 \\
\hline Model 3d & $1.24(0.18-2.29)$ & & $0.86(0.19-1.54)$ & 0.0125 \\
\hline \multicolumn{5}{|l|}{ Potassium } \\
\hline Model 1b & $-1.21(-2.32--0.10)$ & 0.0330 & $-0.29(-1.01-0.44)$ & 0.4372 \\
\hline & -1.10( & 2 & -0.30 & 0.4150 \\
\hline Model 3d & $-1.94(-2.99--0.88)$ & 0.0 & $-0.99(-1.66--0.31)$ & 0.0044 \\
\hline \multicolumn{5}{|c|}{ Sodium-potassium ratio } \\
\hline Model 1b & $1.38(0.58-2.18)$ & 0.0007 & $0.79(0.27-1.31)$ & 0.0031 \\
\hline Model 2c & $1.32(0.50-2.15)$ & 0.0017 & $0.80(0.26-1.34)$ & 0.0035 \\
\hline Model 3d & $1.30(0.50-2.10)$ & 0.0014 & $0.79(0.27-1.30)$ & 0.0026 \\
\hline \multicolumn{5}{|c|}{$\begin{array}{l}\text { a } \beta \text {-coefficients for the usual intake of sodium and potassium are presented } \\
\text { as per } 1 \text { standard deviation (SD); the estimated population SD for } 24 \text {-h } \\
\text { sodium and } 24 \text {-h potassium was } 23.5 \mathrm{mmol} \text { and } 3.0 \mathrm{mmol} \text {, respectively. } \\
\text { The } \beta \text {-coefficient for the sodium-potassium ratio is presented as per } 1 \text { unit } \\
\text { of change in that ratio. bModel } 1 \text { adjusted for age, sex, and study site. In } \\
\text { addition, potassium was included in the model for sodium and sodium in } \\
\text { the model for potassium. cModel } 2 \text { adjusted for all factors in Model } 1 \text { plus } \\
\text { educational attainment, occupation, smoking status, drinking status, } \\
\text { physical activity, and use of antihypertensive medication. dModel } 3 \\
\text { adjusted for all factors in Model } 2 \text { plus BMI as a continuous variable. }\end{array}$} \\
\hline
\end{tabular}

\begin{tabular}{|c|c|c|c|c|c|c|}
\hline \multicolumn{6}{|c|}{ Odds Ratio $(95 \% \mathrm{CI})^{\mathrm{a}}$} & \multirow{2}{*}{$\begin{array}{c}p- \\
\text { Value }\end{array}$} \\
\hline & Q1 & Q2 & Q3 & Q4 & Q5 & \\
\hline \multicolumn{7}{|c|}{ Sodium excretion } \\
\hline Mid-value* & 151 & 175 & 194 & 214 & 245 & \\
\hline Model $1^{b}$ & 1.00 & $1.24(1.08-1.43)$ & $1.48(1.14-1.91)$ & $1.77(1.22-2.58)$ & $2.35(1.34-4.10)$ & 0.0028 \\
\hline Model $2^{c}$ & 1.00 & $1.23(1.07-1.42)$ & $1.45(1.12-1.89)$ & $1.73(1.18-2.53)$ & $2.26(1.28-4.00)$ & 0.0049 \\
\hline Model 3d & 1.00 & $1.19(1.01-1.40)$ & $1.36(1.01-1.82)$ & $1.56(1.02-2.41)$ & $1.95(1.02-3.71)$ & 0.0424 \\
\hline \multicolumn{7}{|c|}{ Potassium excretion } \\
\hline Mid-value* & 23.7 & 26.9 & 29.3 & 31.8 & 35.6 & \\
\hline Model $1^{\mathrm{b}}$ & 1.00 & $0.87(0.76-1.01)$ & $0.79(0.61-1.01)$ & $0.71(0.49-1.02)$ & $0.60(0.36-1.02)$ & 0.0609 \\
\hline Model $2^{c}$ & 1.00 & $0.88(0.76-1.02)$ & $0.80(0.61-1.03)$ & $0.72(0.49-1.05)$ & $0.62(0.35-1.07)$ & 0.0862 \\
\hline Model 3d & 1.00 & $0.74(0.62-0.88)$ & $0.59(0.43-0.80)$ & $0.47(0.30-0.72)$ & $0.33(0.17-0.62)$ & 0.0007 \\
\hline \multicolumn{7}{|c|}{ Sodium-potassium ratio } \\
\hline Mid-value $^{* *}$ & 5.14 & 6.04 & 6.70 & 7.41 & 8.54 & \\
\hline Model 1 ${ }^{b}$ & 1.00 & $1.18(1.07-1.30)$ & $1.33(1.12-1.57)$ & $1.51(1.17-1.93)$ & 1.85 (1.27 - 2.69) & 0.0014 \\
\hline Model $2^{c}$ & 1.00 & $1.17(1.06-1.30)$ & $1.32(1.10-1.57)$ & $1.49(1.15-1.93)$ & $1.82(1.23-2.69)$ & 0.0027 \\
\hline Model 3d & 1.00 & $1.18(1.06-1.31)$ & $1.33(1.10-1.61)$ & $1.52(1.15-1.99)$ & $1.86(1.24-2.81)$ & 0.0030 \\
\hline \multicolumn{7}{|c|}{$\begin{array}{l}\text { *Mid-value of quintile (mmol); }{ }^{* *} \text { Mid-value of quintile; }{ }^{*} \text { For usual intake of sodium and potassium, ORs are } \\
\text { per } 1 \text { standard deviation }(\mathrm{SD}) \text { increase in excretion. For the sodium-potassium ratio, ORs are per } 1 \text { unit of } \\
\text { change. bModel } 1 \text { adjusted for age, sex, and study site. In addition, potassium was included in the model for } \\
\text { sodium and sodium in the model for potassium. cModel } 2 \text { adjusted for all factors in Model } 1 \text { plus educational } \\
\text { attainment, occupation, smoking status, drinking status, physical activity, and use of antihypertensive } \\
\text { medication. dModel } 3 \text { adjusted for all factors in Model } 2 \text { plus BMI as a continuous variable. }\end{array}$} \\
\hline
\end{tabular}

Second, we used a measurement error model to estimate the usual intakes of sodium and potassium and their ratio for the association analysis.

One potential limitation of our study was the method we chose to assess the completeness of urine collection. We did not have an objective biomarker of completeness such as paraaminobenzoic acid (PABA) [34-35]; rather, we employed sensitivity analyses, and used urinary creatinine, urine volume, and body weight to assess the completeness of collection, but our approach might have led to the inclusion of some incomplete urine samples or the exclusion of some complete urine samples, either approach introducing an additional source of variability. Second, in our study, covariates were based on self-reports and thus subject 


\section{Kidney Blood Pressure Research}

Table 7. Adjusted association between usual intake of sodium, potassium, and sodium-potassium ratio and systolic and diastolic blood pressure using the Reinivuo criterion

Table 8. Adjusted odds ratios for hypertension by estimated usual sodium and potassium intake and sodium-potassium ratio using the Reinivuo criterion

$\nabla$

\begin{tabular}{|c|c|c|c|c|}
\hline & \multicolumn{2}{|c|}{ Systolic Blood Pressure } & \multicolumn{2}{|c|}{ Diastolic Blood Pressure } \\
\hline & $\begin{array}{c}\beta \text {-coefficient } \\
(95 \% \mathrm{CI})^{\mathrm{a}}\end{array}$ & $\begin{array}{c}p- \\
\text { Value }\end{array}$ & $\begin{array}{c}\beta \text {-coefficient } \\
(95 \% \mathrm{CI})^{\mathrm{a}}\end{array}$ & $p$-Value \\
\hline \multicolumn{5}{|c|}{ Sodium excretion } \\
\hline Model $1^{b}$ & $2.12(1.14-3.11)$ & $<.0001$ & $1.31(0.67-1.96)$ & $<.0001$ \\
\hline Model $2^{c}$ & $1.99(1.00-2.98)$ & $<.0001$ & $1.27(0.63-1.92)$ & 0.0001 \\
\hline Model 3d & $1.77(0.83-2.73)$ & 0.0002 & $1.10(0.49-1.71)$ & 0.0004 \\
\hline \multicolumn{5}{|c|}{ Potassium excretion } \\
\hline Model $1^{b}$ & $-1.64(-2.63--0.65)$ & 0.0011 & $-0.77(-1.42--0.13)$ & 0.0189 \\
\hline Model 2c & $-1.48(-2.47--0.49)$ & 0.0033 & $-0.76(-1.41--0.12)$ & 0.0205 \\
\hline Model 3d & $-1.85(-2.80--0.90)$ & 0.0001 & $-1.05(-1.67--0.45)$ & 0.0007 \\
\hline \multicolumn{5}{|c|}{ Sodium-potassium ratio } \\
\hline Model 1 ${ }^{b}$ & $1.32(0.71-1.94)$ & $<.0001$ & $0.77(0.37-1.17)$ & 0.0002 \\
\hline Model 2c & $1.28(0.65-1.91)$ & $<.0001$ & $0.77(0.36-1.18)$ & 0.0003 \\
\hline Model 3d & $1.27(0.66-1.87)$ & $<.0001$ & $0.76(0.37-1.15)$ & 0.0001 \\
\hline
\end{tabular}

a $\beta$-coefficients for the usual intake of sodium and potassium are presented as per 1 standard deviation (SD); the estimated population SD for 24-hour sodium and 24-hour potassium was $30.5 \mathrm{mmol}$ and $3.9 \mathrm{mmol}$, respectively. $\beta$-coefficient for the sodium-potassium ratio is presented as per 1 unit of change. ${ }^{b}$ Model 1 adjusted for age, sex, and study site. Potassium intake was included in the model for sodium and sodium intake in the model for potassium. cModel 2 adjusted for all factors in Model 1 plus educational attainment, smoking status, occupation, drinking status, physical activity, and use of antihypertensive medication. dModel 3 adjusted for all factors in Model 2 plus BMI as a continuous variable.

\begin{tabular}{|c|c|c|c|c|c|c|}
\hline & \multicolumn{5}{|c|}{ Odds Ratio $(95 \% \mathrm{CI})^{\mathrm{a}}$} & \multirow{2}{*}{$p$-Value } \\
\hline & Q1 & Q2 & Q3 & Q4 & Q5 & \\
\hline \multicolumn{7}{|l|}{ Sodium } \\
\hline Mid-value* & 126 & 155 & 177 & 201 & 239 & \\
\hline Model 1 ${ }^{\mathrm{b}}$ & 1.00 & $1.17(1.03-1.33)$ & $1.32(1.06-1.65)$ & $1.51(1.09-2.09)$ & $1.86(1.14-3.04)$ & 0.0137 \\
\hline Model 2c & 1.00 & $1.16(1.02-1.32)$ & $1.30(1.04-1.63)$ & $1.48(1.06-2.06)$ & $1.80(1.09-2.96)$ & 0.0211 \\
\hline Model 3d & 1.00 & $1.11(0.97-1.28)$ & $1.21(0.94-1.54)$ & $1.32(0.92-1.89)$ & $1.52(0.88-2.62)$ & 0.1330 \\
\hline \multicolumn{7}{|c|}{ Potassium excretion } \\
\hline Mid-value ${ }^{*}$ & 20.3 & 24.2 & 27.0 & 30.1 & 34.9 & \\
\hline Model $1^{\mathrm{b}}$ & 1.00 & $0.85(0.75-0.97)$ & $0.76(0.61-0.95)$ & $0.67(0.48-0.93)$ & $0.55(0.34-0.89)$ & 0.0155 \\
\hline Model 2c & 1.00 & $0.86(0.75-0.98)$ & $0.77(0.61-0.97)$ & $0.68(0.48-0.95)$ & $0.56(0.34-0.93)$ & 0.0244 \\
\hline Model 3d & 1.00 & $0.80(0.69-0.93)$ & $0.69(0.53-0.88)$ & $0.58(0.40-0.84)$ & $0.44(0.25-0.76)$ & 0.0035 \\
\hline \multicolumn{7}{|c|}{ Sodium-potassium ratio } \\
\hline Mid-value** & 5.02 & 5.94 & 6.65 & 7.41 & 8.67 & \\
\hline Model $1^{\mathrm{b}}$ & 1.00 & $1.11(1.03-1.20)$ & $1.21(1.05-1.38)$ & $1.32(1.07-1.61)$ & $1.52(1.12-2.07)$ & 0.0079 \\
\hline Model 2c & 1.00 & $1.11(1.02-1.20)$ & $1.20(1.04-1.38)$ & $1.30(1.06-1.60)$ & $1.50(1.09-2.06)$ & 0.0128 \\
\hline Model 3d & 1.00 & $1.10(1.01-1.20)$ & $1.19(1.02-1.38)$ & $1.28(1.03-1.60)$ & $1.47(1.05-2.05)$ & 0.0260 \\
\hline \multicolumn{7}{|c|}{$\begin{array}{l}\text { *Mid-value of quintile (mmol); }{ }^{* *} \text { Mid-value of quintile; aFor usual intake of sodium and potassium, ORs are } \\
\text { per } 1 \text { standard deviation (SD) increase in excretion. For sodium-potassium ratio, the OR is } 1 \text { per unit of } \\
\text { change. bModel } 1 \text { adjusted for age, sex, and study site. In addition, potassium was included in the model for } \\
\text { sodium and sodium in the model for potassium. cModel } 2 \text { adjusted for all factors in Model } 1 \text { plus educational } \\
\text { attainment, occupation, smoking status, drinking status, physical activity, and use of antihypertensive } \\
\text { medication. dModel } 3 \text { adjusted for all factors in Model } 2 \text { plus BMI as a continuous variable. }\end{array}$} \\
\hline
\end{tabular}

to reporting error. For example, we did not obtain information on the intensity of physical activity or the amount and frequency of alcoholic beverages the participants consumed. Further, some potential confounding factors, such as total energy intake, were not included as covariates. Finally, this study was cross-sectional, and thus the observed associations should be interpreted with caution. 


\section{Kidney Blood Pressure Research}

Kidney Blood Press Res 2017;42:188-200

DOI: 10.1159/000475486

Published onlIne: April 25, 2017

(C) 2017 The Author(s). Published by S. Karger AG, Basel

Table 9. Adjusted associations with systolic and diastolic blood pressure by usual intake of sodium, potassium, and the sodium-potassium ratio while excluding persons taking an antihypertensive medication

Table 10. Adjusted odds ratios for hypertension by usual sodium and potassium intake and sodium-potassium ratio using the Reinivuo criterion while excluding persons taking an antihypertensive medication

$\nabla$

\begin{tabular}{|c|c|c|c|c|}
\hline & \multicolumn{2}{|c|}{ Systolic Blood Pressure } & \multicolumn{2}{|c|}{ Diastolic Blood Pressure } \\
\hline & $\begin{array}{c}\beta \text {-coefficient } \\
(95 \% \mathrm{CI})^{\mathrm{a}}\end{array}$ & $p$-Value & $\begin{array}{c}\beta \text {-coefficient } \\
(95 \% \mathrm{CI})^{\mathrm{b}}\end{array}$ & $\begin{array}{c}p- \\
\text { Value }\end{array}$ \\
\hline \multicolumn{5}{|l|}{ Sodium } \\
\hline Model 1b & $1.72(0.74-2.68)$ & 0.0005 & $1.18(0.54-1.82)$ & 0.0003 \\
\hline Model $2^{c}$ & $1.56(0.58-2.53)$ & 0.0017 & $1.10(0.46-1.74)$ & 0.0008 \\
\hline Model 3d & $1.27(0.33-2.20)$ & 0.0080 & $0.85(0.25-1.46)$ & 0.0059 \\
\hline \multicolumn{5}{|l|}{ Potassium } \\
\hline Model $1^{\mathrm{b}}$ & $-1.03(-2.63--0.65)$ & 0.0369 & $-0.58(-1.22-0.06)$ & 0.0773 \\
\hline Model 2c & $-0.91(-1.88-0.06)$ & 0.0657 & $-0.57(-1.21-0.07)$ & 0.0832 \\
\hline Model 3d & $-1.25(-2.19--0.31)$ & 0.0089 & $-0.83(-1.44--0.23)$ & 0.0072 \\
\hline \multicolumn{5}{|c|}{ Sodium-potassium ratio } \\
\hline Model $1^{\mathrm{b}}$ & $0.98(0.37-1.60)$ & 0.0017 & $0.64(0.23-1.05)$ & 0.0020 \\
\hline Model 2c & $0.91(0.28-1.54)$ & 0.0045 & $0.63(0.21-1.04)$ & 0.0032 \\
\hline Model 3d & $0.86(0.25-1.47)$ & 0.0056 & $0.59(0.19-0.98)$ & 0.0038 \\
\hline
\end{tabular}

a $\beta$-coefficients for usual intake of sodium and potassium are presented as per 1 standard deviation (SD); the estimated population SD for 24-h sodium and 24 -h potassium was $24.6 \mathrm{mmol}$ and $3.3 \mathrm{mmol}$, respectively. $\beta$ coefficient for the sodium-potassium ratio is presented as per 1 unit of change. bModel 1 adjusted for age, sex, and study site. In addition, the model adjusted for potassium in the sodium model and sodium in the potassium model. cModel 2 adjusted for all factors in Model 1 plus educational attainment, occupation, smoking status, drinking status, physical activity, and use of antihypertensive medication. dModel 3 adjusted for all factors in Model 2 plus BMI as a continuous variable.

\begin{tabular}{|c|c|c|c|c|c|c|}
\hline & \multicolumn{5}{|c|}{ Odds Ratio (95\% CI) a } & \multirow{2}{*}{$\begin{array}{c}p- \\
\text { Value }\end{array}$} \\
\hline & Q1 & Q2 & Q3 & Q4 & Q5 & \\
\hline \multicolumn{7}{|l|}{ Sodium } \\
\hline Mid-value* & 118 & 144 & 163 & 183 & 216 & \\
\hline Model $1^{\mathrm{b}}$ & 1.00 & $1.23(1.07-1.41)$ & $1.43(1.12$ - 1.82) & $1.67(1.18-2.37)$ & $2.16(1.28-3.67)$ & 0.0041 \\
\hline Model 2c & 1.00 & $1.21(1.05-1.40)$ & $1.39(1.08-1.78)$ & $1.61(1.12-2.30)$ & $2.05(1.19-3.51)$ & 0.0093 \\
\hline Model 3d & 1.00 & $1.15(0.99-1.34)$ & $1.28(0.98-1.67)$ & $1.42(0.97-2.10)$ & $1.70(0.95-3.05)$ & 0.0743 \\
\hline \multicolumn{7}{|l|}{ Potassium } \\
\hline Mid-value* & 18.8 & 22.3 & 24.9 & 27.6 & 31.9 & \\
\hline Model 1b & 1.00 & $0.86(0.75-0.99)$ & $0.77(0.61-0.98)$ & $0.69(0.49-0.97)$ & $0.58(0.35-0.96)$ & 0.0323 \\
\hline Model $2^{c}$ & 1.00 & $0.87(0.76-1.00)$ & $0.78(0.61-1.00)$ & $0.70(0.49-1.00)$ & $0.59(0.35-1.00)$ & 0.0528 \\
\hline Model 3d & 1.00 & $0.82(0.70-0.96)$ & $0.71(0.54-0.92)$ & $0.61(0.41-0.89)$ & $0.48(0.27-0.84)$ & 0.0108 \\
\hline \multicolumn{7}{|c|}{ Sodium-potassium ratio } \\
\hline Mid-value ${ }^{* *}$ & 5.02 & 5.92 & 6.62 & 7.38 & 8.61 & \\
\hline Model $1^{\mathrm{b}}$ & 1.00 & $1.12(1.03-1.21)$ & $1.22(1.06-1.40)$ & $1.34(1.09-1.65)$ & $1.56(1.14-2.13)$ & 0.0057 \\
\hline Model $2^{c}$ & 1.00 & $1.11(1.02-1.20)$ & $1.20(1.04-1.39)$ & $1.32(1.06-1.63)$ & $1.52(1.10-2.10)$ & 0.0112 \\
\hline Model 3d & 1.00 & $1.10(1.01-1.20)$ & $1.19(1.02-1.38)$ & $1.28(1.03-1.60)$ & $1.46(1.04-2.05)$ & 0.0272 \\
\hline \multicolumn{7}{|c|}{$\begin{array}{l}\text { *Mid-value of quintile (mmol); }{ }^{* *} \text { Mid-value of quintile; aFor usual intake of sodium and potassium, odds ratios } \\
\text { (ORs) are per } 1 \text { standard deviation (SD) increase in excretion. For sodium-potassium ratio, the OR is per unit } \\
\text { of change. bModel } 1 \text { adjusted for age, sex, and study site. Potassium was included in the model for sodium and } \\
\text { sodium was included in the model for potassium. }{ }^{\circ} \text { Model } 2 \text { adjusted for all factors in Model } 1 \text { plus educational } \\
\text { attainment, occupation, smoking status, drinking status, physical activity, and use of antihypertensive } \\
\text { medication. dModel } 3 \text { adjusted for all factors in Model } 2 \text { plus BMI as a continuous variable }\end{array}$} \\
\hline
\end{tabular}

\section{Conclusion}

Our results indicate that sodium intake is positively associated with $\mathrm{BP}$, that potassium intake is negatively associated with both BP and risk of hypertension, and that the sodiumto-potassium ratio is positively associated with both. These results are consistent with previous findings, and demonstrate the compelling importance of reducing sodium intake to 


\section{Kidney Blood Pressure Research}

control BP. Our study suggested that reducing sodium and increasing potassium intake is a public health priority for these survey areas.

\section{Disclosure Statement}

The authors declare no conflict of interest.

\section{Acknowledgments}

We acknowledge all the survey investigators from the national, Shandong, and Jiangsu provincial and county-level CDCs and all participants in the survey. We thank Quanhe Yang, Yuling Hong, Ying Cai, Barbara Bowman, Zefeng Zhang, USCDC, for their assistance and advice. We thank Dr. Alicia L. Carriquiry, Iowa State University, for her advice on using the software program PC-SIDE (Software for Intake Distribution Estimation for the Windows OS, Iowa State University, Version 1.0) to estimate the usual intake of sodium, potassium and sodium-potassium ratio.

The survey on which this study was based was funded by the Chinese Center for Disease Control and Prevention and the US Centers for Disease Control and Prevention.

\section{References}

1 Yan S, Li J, Li S, Zhang B, Du S, Gordon-Larsen P, Adair L, Popkin B: The expanding burden of cardiometabolic risk in China: The China Health and Nutrition Survey. Obes Rev 2012;13:810-821.

2 He J, Gu D, Wu X, Reynolds K, Duan X, Yao C, Wang J, Chen CS, Chen J, Wildman RP, Klag MJ, Whelton PK: Major causes of death among men and women in China. N Engl J Med 2005;353:1124-1134.

3 Ministry of Health: Annual Report on Health Statistics. Beijing, Peking Union Medical College Publishing House, 2010.

$4 \quad$ China CDC \& China News: Salt reduction and hypertension prevention. Beijing, China News Service, 2011.

$5 \quad$ National Center for Cardiovascular Disease, China: Report on Cardiovascular Diseases in China (2013). Beijing, Encyclopedia of China Publishing, 2014.

6 Adrogué HJ, Madias NE: Sodium and potassium in the pathogenesis of hypertension. N Engl J Med 2007;356:1966-1978.

7 Elliott P, Walker LL, Little MP, Blair-West JR, Shade RE, Lee DR, Rouquet P, Leroy E, Jeunemaitre X, Ardaillou R, Paillard F, Meneton P, Denton DA: Change in salt intake affects blood pressure of chimpanzees: Implications for human populations. Circulation 2007;116:1563-1568.

-8 Aburto NJ, Hanson S, Gutierrez H, Hooper L, Elliott P, Cappuccio FP: Effect of increased potassium intake on cardiovascular risk factors and disease: Systematic review and meta-analyses. BMJ 2013;346:f1378.

-9 Whelton PK, He J, Cutler JA, Brancati FL, Appel LJ, Follmann D, Klag MJ: Effects of oral potassium on blood pressure. Meta-analysis of randomized controlled clinical trials. JAMA 1997;277:1624-1632.

-10 He FJ, MacGregor GA: Reducing population salt intake worldwide: from evidence to implementation. Prog Cardiovasc Dis 2010;52:363-382.

11 Murray CJ, Lauer JA, Hutubessy RC, Niessen L, Tomijima N, Rodgers A, Lawes CM, Evans DB: Effectiveness and costs of interventions to lower systolic blood pressure and cholesterol: a global and regional analysis on reduction of cardiovascular-disease risk. Lancet 2003;361:717-725.

12 Barton P, Andronis L, Briggs A, McPherson K, Capewell S: Effectiveness and cost effectiveness of cardiovascular disease prevention in whole populations: modeling study. BMJ 2011;343:d4044.

13 The INTERSALT Co-operative Research Group: INTERSALT Study an international co-operative study on the relation of blood pressure to electrolyte excretion in populations. I. Design and methods. J Hypertens 1986;4:781-787. 


\section{Kidney \\ Blood Pressure Research}

14 Guenther PM, Kott PS, Carriquiry AL: Development of an approach for estimating usual nutrient intake distributions at the population level. J Nutr 1997;127:1106-1112.

15 Liu LS: 2010 Chinese guidelines for the management of hypertension. Chin J Cardiol 2011;39:579-615.

16 Bureau of Disease Control and Prevention, China's Ministry of Health: Chinese Guideline on Adult Overweight and Obesity Prevention. Beijing, People's Medical Publishing House, 2006.

17 Desquilbet L, Mariotti F: Dose-response analyses using restricted cubic spline functions in public health research. Stat Med 2010;29:1037-1057.

18 WHO Regional Office for Europe: Estimation of Sodium Intake and Output: Review of Methods and Recommendations for Epidemiological Studies. Report on a WHO Meeting by the WHO Collaborating Center for Research and Training in Cardiovascular Diseases. Geneva, World Health Organization, 1984.

19 Reinivuo H, Valsta LM, Laatikainen T, Tuomilehto J, Pietinen P: Sodium in the Finnish diet: Trends in dietary sodium intake and comparison between intake and 24-h excretion of sodium. Eur J Clin Nutr 2006;60:1160-1167.

20 Cutler JA, Follmann D, Allender PS: Randomized trials of sodium reduction: An overview. Am J Clin Nutr 1997;65:643S-651S.

21 Cutler JA, Follmann D, Elliot P, Suh I: An overview of randomized trials of sodium reduction and blood pressure. Hypertension 1991;17:I27- I33.

22 He F, MacGregor G: Effects of modest salt reduction on blood pressure: A meta-analysis of randomized trials: Implications for public health. J Hum Hypertens 2002;16:761-770.

-23 Graudal NA, Galloe AM, Garred P: Effects of sodium restriction on blood pressure, renin, aldosterone, catecholamines, cholesterols, and triglyceride: A meta-analysis. JAMA 1998;279:1383-1391.

-24 Elliott P: Observational studies of salt and blood pressure. Hypertension 1991;17:I3-I8.

-25 Intersalt Cooperative Research Group: Intersalt: An international study of electrolyte excretion and blood pressure. Results from 24 hour urinary sodium and potassium excretion. BMJ 1988;297:319-328.

26 Mente A, O`Donnell MJ, Rangarajan S, McQueen MJ, Poirier P, Wielgosz A, Morrison H, Li W, Wang X, Di C, Mony P, Devanath A, Rosengren A, Oguz A, Zatonska K, Yusufali AH, Lopez-Jaramillo P, Avezum A, Ismail N, Lanas F, Puoane T, Diaz R, Kelishadi R, Iqbal R, Yusuf R, Chifamba J, Khatib R, Teo K, Yusuf S: Association of urinary sodium and potassium excretion with blood pressure. N Engl J Med 2014;371:601-611.

-27 Zhang Z, Cogswell ME, Gillespie C, Fang I, Loustalot F, Dai S, Carriquiry AL, Kuklina EV, Hong Y, Merritt R, Yang Q: Association between usual sodium and potassium intake and blood pressure and hypertension among U.S. adults: NHANES 2005-2010. PLoS One 2013;8:e75289.

-28 Dickinson HO, Nicolson DJ, Campbell F, Beyer FR, Mason J: Potassium supplementation for the management of primary hypertension in adults. Cochrane Database Syst Rev 2006;3:CD004641.

29 Whelton PK, He J, Cutler JA, Brancati FL, Appel LJ, Follmann D, Klag MJ: Effects of oral potassium on blood pressure. Meta-analysis of randomized controlled clinical trials. JAMA 1997;277:1624-1632.

-30 D’Elia L, Barba G, Cappuccio FP, Strazzullo P: Potassium intake, stroke, and cardiovascular disease: A metaanalysis of prospective studies. J Am Coll Cardiol 2011;57:1210-1219.

-31 Liu L, Liu L, Ding Y, Huang Z, He B, Sun S, Zhao G, Zhang H, Miki T, Mizushima S, Ikeda K, Nara Y, Yamori Y: Ethnic and environmental differences in various markers of dietary intake and blood pressure among Chinese Han and three other minority peoples of China: Results from the WHO Cardiovascular Diseases and Alimentary Comparison (CARDIAC) Study. Hypertens Res 2001;24:315-322.

32 Perez V, Chang ET: Sodium-to-potassium ratio and blood pressure, hypertension, and related factors. Adv Nutr 2014;5:712-741.

33 Du S, Batis C, Wang H, Zhang B, Zhang J, Popkin BM: Understanding the patterns and trends of sodium intake, potassium intake, and sodium to potassium ratio and their effect on hypertension in China. Am J Clin Nutr 2014;99:334-343.

-34 Bingham S, Cummings JH: The use of 4-aminobenzoic acid as a marker to validate the completeness of $24 \mathrm{~h}$ urine collections in man. Clin Sci (Lond) 1983;64:629-635.

35 Murakami K, Sasaki S, Takahashi Y, Uenishi K, Watanabe T, Kohri T, Yamasaki M, Watanabe R, Baba K, Shibata K, Takahashi T, Hayabuchi H, Ohki K, Suzuki J: Sensitivity and specificity of published strategies using urinary creatinine to identify incomplete 24-h urine collection. Nutrition 2008;24:16-22. 